\title{
Finite difference modeling of heat distribution in multilayer soils with time-spatial hydrothermal properties
}

\author{
Hossein Nowamooz a, *, Saeid Nikoosokhan ${ }^{\mathrm{a}}$, Jian Lin ${ }^{\mathrm{b}}$, Cyrille Chazallon ${ }^{\mathrm{a}}$ \\ a ICUBE, UMR 7357, CNRS, INSA de Strasbourg, 24 boulevard de la Victoire, 67084 Strasbourg, France \\ b ICUBE, UMR 7357, CNRS, Université de Strasbourg, 72 route du Rhin, 67400 Illkirch, France
}

\section{A R T I C L E I N F O}

\section{Article history:}

Received 14 September 2014

Accepted 4 November 2014

Available online

\section{Keywords:}

Finite difference method

Multilayered soil heat distribution

Time-spatial variable thermal diffusivity

Homogeneous soil

\begin{abstract}
A B S T R A C T
In this study, the heat distribution throughout the profile of unsaturated multilayered soil is determined using finite difference method while its thermal diffusivity varies with time and depth. First, the input parameters such as water content, dry density and sand content of the soil profile are provided. These data are coupled with the theoretical approaches to estimate thermal properties of soil such as thermal conductivity and thermal diffusivity of multilayered soil. Second, finite difference method is used to model heat distributions in soil profile taking into account the initial and boundary conditions. A continuity of heat flux between each layer is performed as a condition in the numerical model. A comparison of estimated temperature within time throughout the profile with the thermal probe measurements shows a satisfactory capacity of the numerical model. Finally, different cases of nonhomogeneous and homogeneous soil show that thermal response of homogeneous and nonhomogeneous soils are almost similar at average value of thermal diffusivity where hydrothermal characteristics of each soil layer (such as water content, dry density, and soil texture) are required to calculate this average value.
\end{abstract}

(c) 2014 Elsevier Ltd. All rights reserved.

\section{Introduction}

A shallow geothermal energy system is considered as a significant source of thermal energy suitable for heating and cooling of individual buildings. It is a renewable source of energy as heat transfers continuously in the soil due to temperature gradient between the bottom of the earth and the air [1].

Since 1980, researchers have widely considered soils for heating or cooling purposes of seasonal thermal energy storage applications, e.g., Refs. [2-8]. Thermal energy can be stored for long time in the underground soil [9]. The development of ground coupled heat pump (GCHP) has been promoted since environmental problems exist [10-12]. Several advantages of using underground soil as heat source for GCHP compared with the traditional air source heat pump, encourage researchers to understand more about thermal behavior of soil [13-16].

Soil temperature is considered to be an important parameter in geothermal energy applications such as the passive heating and cooling of buildings including performance, dimensions, and

\footnotetext{
* Corresponding author.

E-mail address: hossein.nowamooz@insa-strasbourg.fr (H. Nowamooz).
}

installation cost in many geothermal applications [17-20]. In shallow grounds, just $20 \mathrm{~m}$ below the surface, the soil maintains nearly constant temperature ranging between 10 and 20, depending on the region [21]. In this context, for the seasonal heat storage (studied in this work) such as earth to air heat exchanger (EAHEs), and GSHPs, the soil temperature is considered to be nearly constant for the depths higher than $20 \mathrm{~m}$ [22-24].

Hydrothermal properties of soil have been widely studied in geothermal issues. Soil thermal properties are important inputs for models of soil temperature, but those thermal properties vary while the water content in soil changes. Many researchers have studied the dependence of thermal diffusivity of soil with other soil characteristics as well as degree of saturation [25-30]. However, conventional schemes consider constant thermal properties to give hydrothermal response of soil [31-33]. Ozgener et al. [34] developed a model to predict daily soil temperatures using a sinusoidal function of time and depth. In their work, transient heat flow principles were used with assumptions of one dimensional heat flow, homogeneous soil, and constant thermal diffusivity. Such hypothesis cannot take into account a comprehensive understanding of the effects of thermal properties due to the fact that those properties vary with soil physical characteristics such as soil texture and water content. 
Furthermore, the commercial computer codes taking in consideration the hydrothermal properties variation are not able to attribute different hydrothermal properties of different soil layers for a same profile. It is necessary to develop a code which can calculate the variation of hydrothermal properties of multilayers for one soil profile while applying heat flux continuity at the interface of each layer of soil profile.

In this study, the input parameters of an in-situ soil such as water content, dry density, and sand content of the soil profile are initially measured for different layers with time and depth. Using theoretical approaches, thermal properties of multilayered soil such as thermal conductivity and thermal diffusivity are also determined for the different time and depth. Finally, the finite difference model is applied on this multilayered profile to capture its temperature variation with time and depth.

\section{Numerical model}

In this section, heat distributions throughout a multilayer profile of soil are obtained by considering variable thermal diffusivity. Fig. 1 shows a multilayer profile of soil with different soil texture and soil density in each layer $i$. Moreover, soil degree of saturation varies with time and depth throughout the profile.

Therefore, thermal diffusivity of soil changes with time and depth for which the transient heat distribution in soil is governed by:

$\frac{\partial T}{\partial t}=\alpha(z, t)\left(\frac{\partial^{2} T}{\partial z^{2}}\right)+\frac{\partial \alpha(z, t)}{\partial z} \frac{\partial T}{\partial z}$

where $\alpha(z ; t)$ is the thermal diffusivity of soil which varies with time and space.

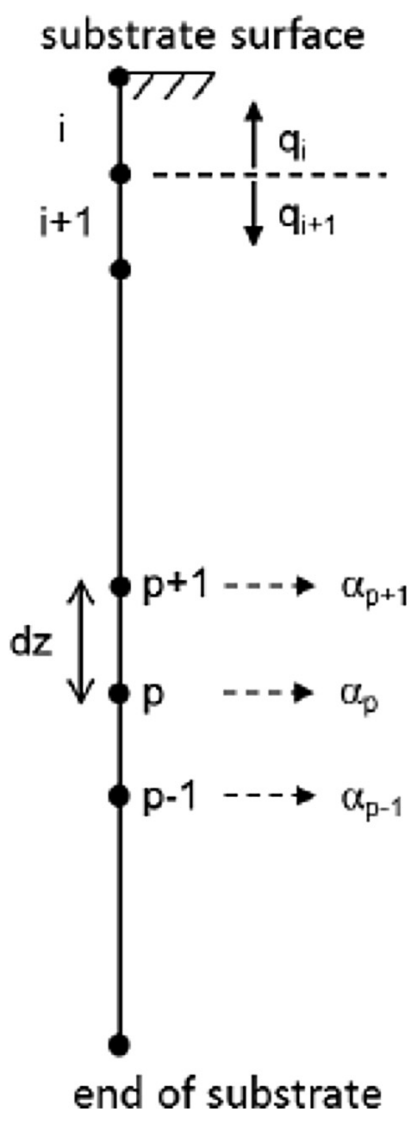

Fig. 1. Node arrangement in the finite difference formulation.
The model is subjected to the boundary conditions:

$\frac{\partial T}{\partial z}\left(z=L_{\infty}\right)=0$

which shows there is no heat flux at large depth.

$T(z=0, t)=T_{\mathrm{s}}(t)$

where $T_{\mathrm{s}}(t)$ is the measured surface temperature.

Moreover, at the interface between two layers, two boundary conditions must be satisfied. The continuity of temperature:

$T_{i}\left(z=L_{i}, t\right)=T_{i+1}\left(z=L_{i}, t\right)$

and the continuity of the heat flux:

$-\lambda_{i}\left(z=L_{i}, t\right) \frac{\mathrm{d} T_{i}}{\mathrm{~d} z}\left(z=L_{i}\right)=-\lambda_{i+1}\left(z=L_{i}, t\right) \frac{\mathrm{d} T_{i+1}}{\mathrm{~d} z}\left(z=L_{i}\right)$

Using finite difference method, a series of nodes within the substrate which span from the surface to a defined depth is considered as shown in Fig. 1. For each node $p$, there exists a thermal diffusivity value $\alpha(p)$. At a general node $p$, the differential terms in Eq. (1) can be approximated using the following expressions.

$\frac{\partial T}{\partial t}=\frac{T_{p}^{k+1}-T_{p}^{k}}{\Delta t}$

$\frac{\partial^{2} T}{\partial z^{2}}=\frac{T_{p+1}^{k}-2 T_{p}^{k}+T_{p-1}^{k}}{\Delta^{2} z}$

$\frac{\partial \alpha(z, t)}{\partial z} \frac{\partial T}{\partial z}=\frac{\alpha_{p+1}^{k}-\alpha_{p-1}^{k}}{2 \Delta z} \frac{T_{p+1}^{k}-T_{p-1}^{k}}{2 \Delta z}$

The temporal temperature derivative Eq. (6) is evaluated as the difference between the future time step $k+1$, and the present time step $k$, so that an explicit scheme is obtained. Considering that thermal diffusivities at each time $k$ and depth $p$ are known parameters; thus, in the finite difference scheme described by Eqs. (7) and (8), thermal diffusivities as well as spatial temperature derivatives are evaluated at time $k$ (we have not used a distributed lag model).

The temperature $T$ at time $k+1$ is computed in each iteration until the difference of temperature between two iterations becomes less than $10^{-4}$. Normally for the convergence, it is enough to have $\operatorname{Max}\left(\alpha(z, t) \mathrm{d} t / \mathrm{d} z^{2}\right)<0.5$ by considering thermal diffusivities at each time $k$, and depth $p$.

The continuity conditions are applied at the interface of each soil layer $i$ where the soil textures and dry density of soil changed.

\section{Input parameters of the numerical model}

This section is dedicated to the model input parameters such as degree of saturation, thermal diffusivity and temperature within depth and time.

\subsection{Field description}

Since September 2012, a field located in Illkirch, Alsace in France was instrumented with five temperature probes $\mathrm{TS}_{20}, \mathrm{TS}_{21}, \mathrm{TS}_{22}$, $\mathrm{TS}_{23}$, and $\mathrm{TH}_{50}$ and one humidity probe $H_{\mathrm{S}}$. The field is composed of three in-situ soils: vegetarian soil, wind-blown sandy soil and soil backfill (see Fig. 2). 


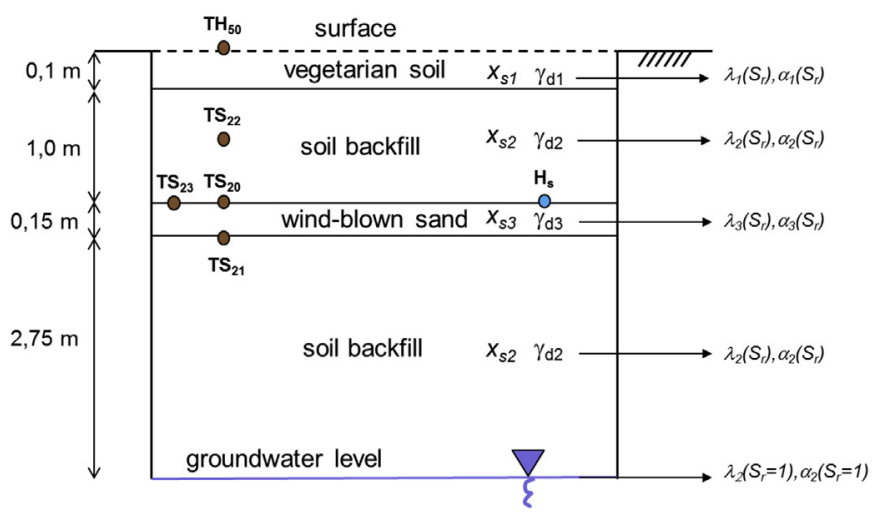

Fig. 2. Multilayered soil with different sand content $x_{\mathrm{s}}$ and dry density $\gamma_{\mathrm{d}}$ in each layer. $\mathrm{TS}_{20}, \mathrm{TS}_{21}, \mathrm{TS}_{22}, \mathrm{TS}_{23}$, and $\mathrm{TH}_{50}$ are thermal probes while $H_{\mathrm{S}}$ is humidity probe.

\subsection{Profile of water content and degree of saturation of multilayered soil}

A core sampling from the soil profile is performed as it is shown in Fig. 3. Then, water content of each sample is measured gravimetrically by over drying them at $60{ }^{\circ} \mathrm{C}$. This initial water content profile is called $W_{0}(z)$. Soil at groundwater level in the field $(z=4 \mathrm{~m})$ is considered to be in saturated state $(\mathrm{Sr}=100 \%)$. Soil water content between the deepest in-situ measured data $(z=0: 87 \mathrm{~m})$ and the ground water level $(z=4 \mathrm{~m})$ is considered to vary exponentially until it arrives at the saturation degree at the underground water level.

Water content of soil was also measured by a humidity probe $H_{\mathrm{S}}$ at the depth of $1.11 \mathrm{~m}$ (Fig. 2). The value of water content is shown as a red spot in Fig. 3 which agrees well with the one measured by core sampling at the same position and time.

Humidity probe $H_{\mathrm{S}}$ measured the water content of soil during the year (see Fig. 4). A coefficient $\Gamma$ which is given as:

$\Gamma(t)=\frac{W(t)}{W\left(z=z_{\mathrm{HS}}\right)}$

where $W(t)$ is the water content measured by humidity probe $H_{\mathrm{S}}$ during one year and $W_{0}\left(z=z_{\mathrm{HS}}\right)$ is the initial water content at the depth of the probe $H_{\mathrm{S}}$ measured at $t=0$. By multiplying the coefficient $\Gamma(t)$ and the initial water content profile $W_{0}(z)$, the water content throughout the soil profile and within time $W(z, t)$ is given:

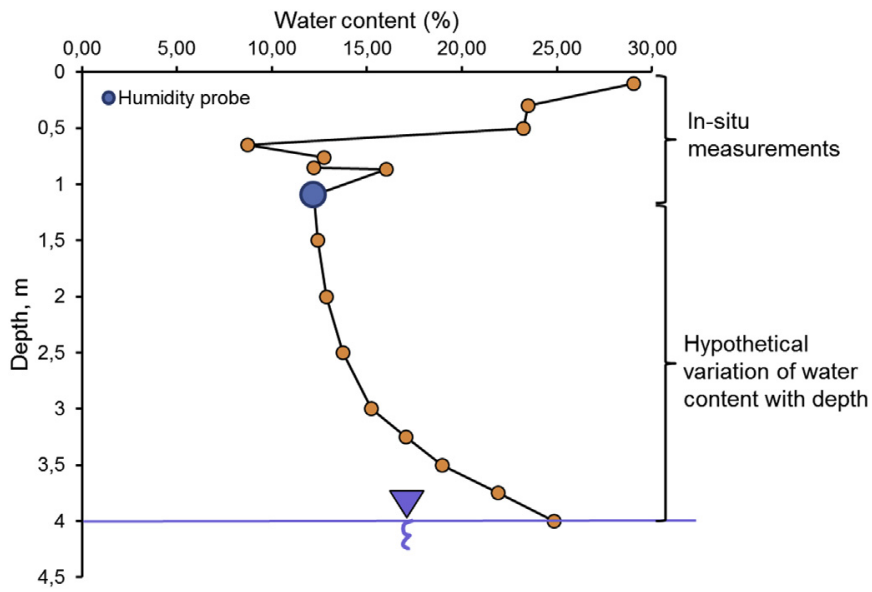

Fig. 3. Initial water content profile $W_{0}(z)$ performed by core sampling.

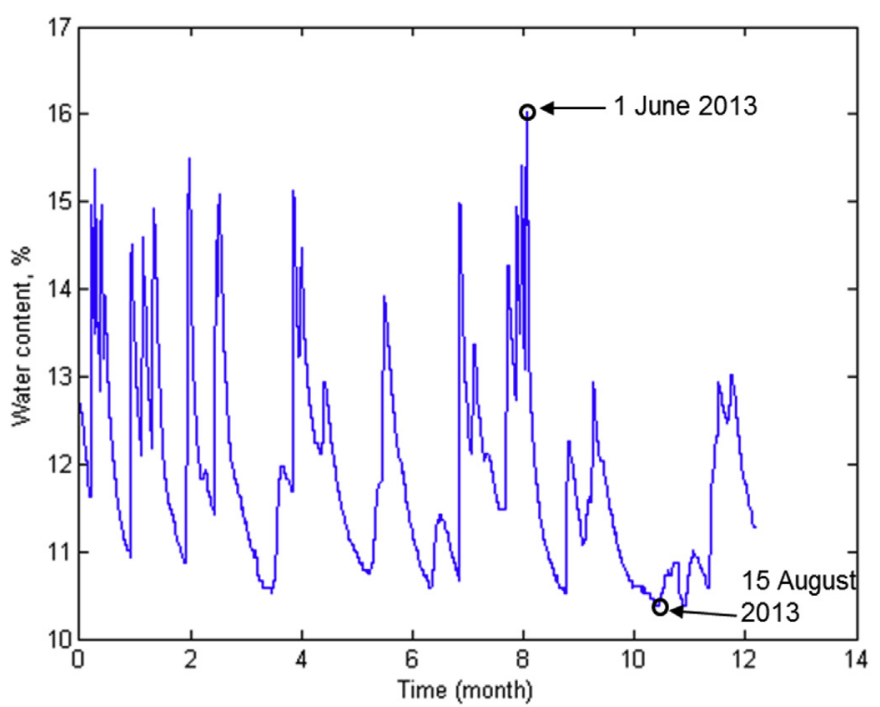

Fig. 4. Measured water content by humidity probe $w_{\mathrm{HS}}$ during one year.

$W(z, t)=\Gamma(t) \cdot W_{0}(z)$

Fig. 5 shows the maximum and minimum bounds of water content profiles during one year, which correspond to the profile of 1 June 2013 and that of 15 August 2013. It is worthwhile noting that underground water level increases from depth $4 \mathrm{~m}$ to $3.6 \mathrm{~m}$ during this period.

The profile of dry density $\gamma_{\mathrm{d}}(z)$ is also taken as it is described in Fig. 6. Dry density of soil between the deepest in-situ measured data $(z=0.87 \mathrm{~m})$ and the ground water level $(z=4 \mathrm{~m})$ is considered to be constant and equals to $\gamma_{\mathrm{d}}=16 \mathrm{kN} \mathrm{m}^{-3}$.

Knowing dry density and water content profile, the time-space degree of saturation of soil $\mathrm{Sr}(z, t)$ can be easily determined by the following equation:

$\operatorname{Sr}(z, t)=W(z, t) \cdot G_{\mathrm{s}} /\left(\left(\frac{G_{\mathrm{s}} \cdot \gamma_{\mathrm{W}}}{\gamma_{\mathrm{d}}(z)}\right)-1\right)$

where $G_{s}$ is the soil specific gravity taken constant equal to 2.65 and $\gamma_{w}$ is the unit weight of water taken constant equal to $10 \mathrm{kN} / \mathrm{m}^{3}$.

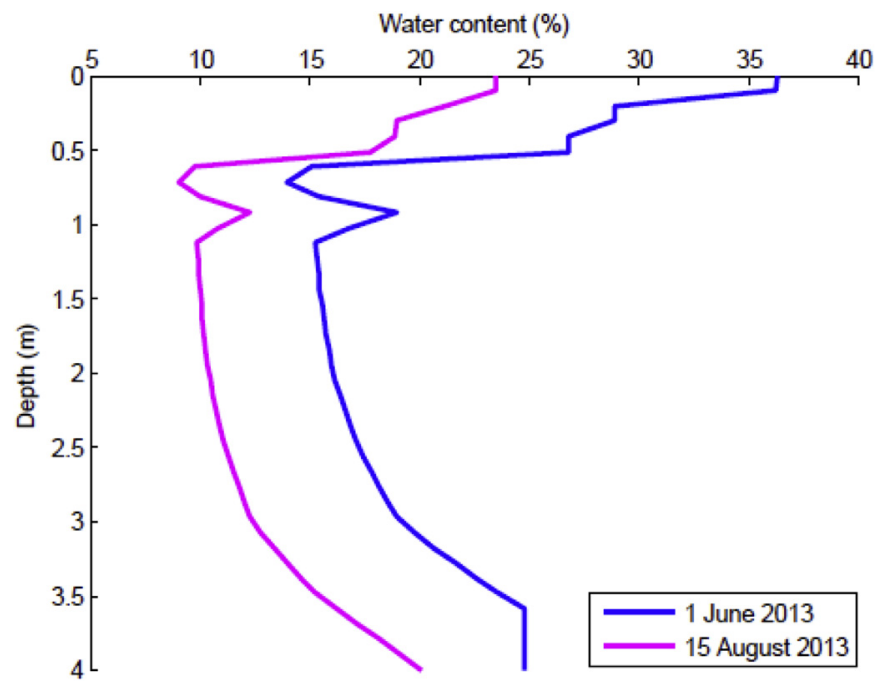

Fig. 5. Maximum and minimum bounds of water content profiles of multilayered soil corresponding to the profile of 1 June 2013 and that of 15 August 2013. 


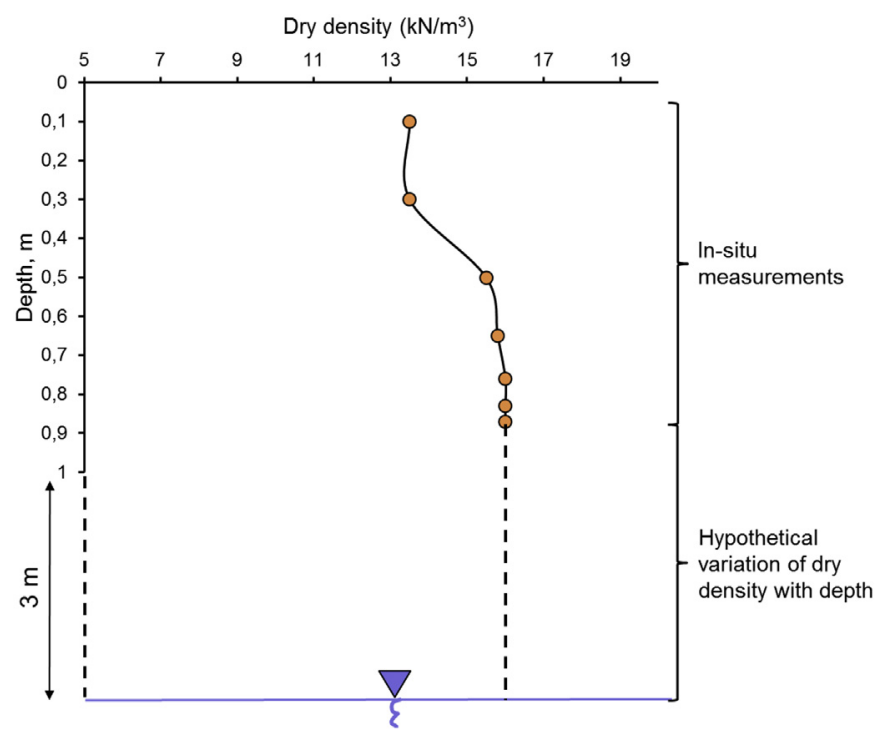

Fig. 6. Initial estimated dry density performed by core sampling.

\subsection{Measurements of thermal properties of multilayered soil}

For the layers of vegetarian and wind-blown sandy soils, a handheld device named KD2 Pro [35] is used to measure the thermal properties of the soil. The moist soil of each layer is then compacted into a column $(50 \mathrm{~mm}$ inner diameter and $100 \mathrm{~mm}$ high) to reach a desired dry density. The compacted samples are sealed and placed in a constant temperature room $\left(20 \pm 1^{\circ} \mathrm{C}\right)$ for $24 \mathrm{~h}$ before measurements to ensure thermal equilibrium between water and soil. Soil thermal properties $(\lambda$ and $C$ ) are determined with the algorithm for the dual needle probe based on the line heat source analysis given in Carslaw and Jaeger [36] and Kluitenberg et al. [37]. A (30 mm long, $1.3 \mathrm{~mm}$ diameter) dual needle SH-1 sensor is inserted carefully into each soil column, and current is applied to the sensors to produce a heat pulse. Heat-pulse measurements are repeated two times on each soil column.

Thermal properties of the soil backfill are measured with another method called stationary guarded-hot-plate method [38]. This method is more appropriate for the soil backfill as the size of the largest soil constituent is more than the distance between the duel needles of KD2 Pro device which is $5 \mathrm{~mm}$. The plate size is $40 \mathrm{~cm} \times 60 \mathrm{~cm}$, the thickness of soil samples is less than $8 \mathrm{~cm}$ to ensure one dimensional thermal transfer. Thermal conductivity $\lambda$ is then determined by the heat flow, the mean temperature difference between the sample surfaces and the dimensions of the samples. The same test apparatus was used to measure the soil thermal capacity $C$ with the help of an insulation cover on the soil samples.

Thermal diffusivity $\alpha$ of soil is taken from two other thermal parameters, i.e., thermal conductivity $\lambda$ and thermal capacity $C$ of soil:

$\alpha=\frac{\lambda}{C}$

Figs. 7-9 show measured thermal properties ( $\lambda$ and $\alpha$ ) of the three soil layers: vegetarian soil, wind-blown sandy soil, and soil backfill, respectively. The error bars of $10 \%$ in the experimental data are also reported in these figures. The thermal conductivity increases with respect to the degree of saturation while the thermal diffusivity has a maximum value around the degree of saturation of $50 \%$ for all the studied soils. Such a behavior was also observed by other researchers for the sandy soil [39]. a)
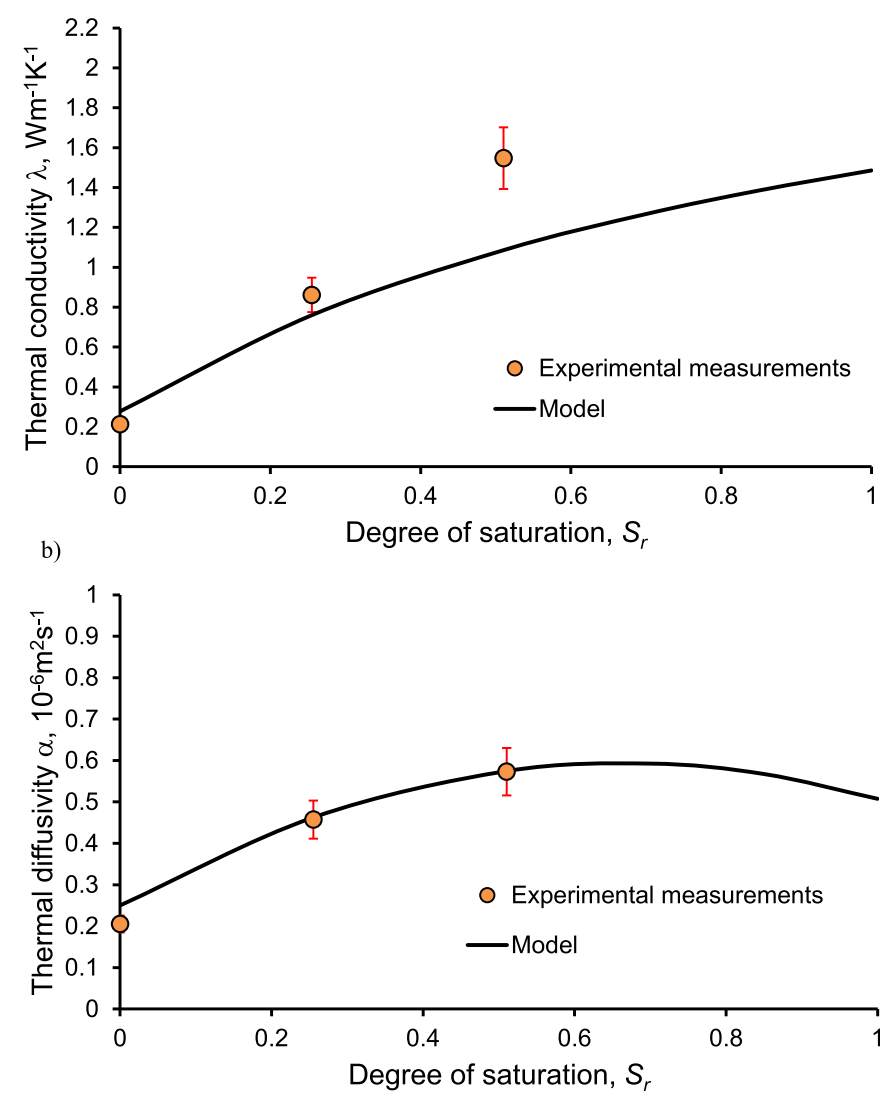

Fig. 7. Comparison of the theoretical models and the measurements of vegetarian soil thermal properties: a) thermal conductivity $\lambda$, and b) thermal diffusivity $\alpha$, performed with KD2 Pro method.

\subsection{Prediction of thermal properties of multilayered soil}

In this section, theoretical relationships for each parameter, thermal conductivity $\lambda$ and thermal diffusivity, $\alpha$ are proposed.

Using the concept of normalized thermal conductivity [28], thermal conductivity is defined as:

$\lambda=\left(\lambda_{\text {sat }}-\lambda_{\mathrm{dry}}\right) K_{\lambda}+\lambda_{\mathrm{dry}}$

where $\lambda_{\text {dry }}$ and $\lambda_{\text {sat }}$ are the thermal conductivity of dry and saturated soils $\left(\mathrm{Wm}^{-1} \mathrm{~K}^{-1}\right)$, respectively.

The measured thermal conductivity values from eight soils from China [40] are used to calibrate the proposed model. A set of linear relationships is proposed for the fitting functions adapted to those data $[41,42]$ :

$$
\begin{aligned}
& \lambda_{\mathrm{sat}}=a x_{\mathrm{s}}+b \gamma_{\mathrm{d}} \\
& \lambda_{\mathrm{dry}}=c x_{\mathrm{s}}+d \gamma_{\mathrm{d}}
\end{aligned}
$$

where $a$ and $b$ are fitted parameters for saturated thermal conductivity equal to $0.53 \mathrm{~W} \mathrm{~m}^{-1} \mathrm{~K}^{-1}$ and $0.1 \mathrm{~W} \mathrm{~m}^{2} \mathrm{~K}^{-1}(\mathrm{kN})^{-1}$, respectively, and where $c$ and $d$ are fitted parameters for unsaturated thermal conductivity equal to $0.087 \mathrm{~W} \mathrm{~m}^{-1} \mathrm{~K}^{-1}$ and $0.019 \mathrm{~W} \mathrm{~m}^{2} \mathrm{~K}^{-1}(\mathrm{kN})^{-1}$, respectively (Least Square Regression Coefficient $R^{2}$ higher than 0.8 for all fitted parameters).

To relate normalized thermal conductivity $K_{\lambda}$ to the degree of saturation Sr, the equation proposed by Coté and Konrad (2005) [43] is used: 
a)

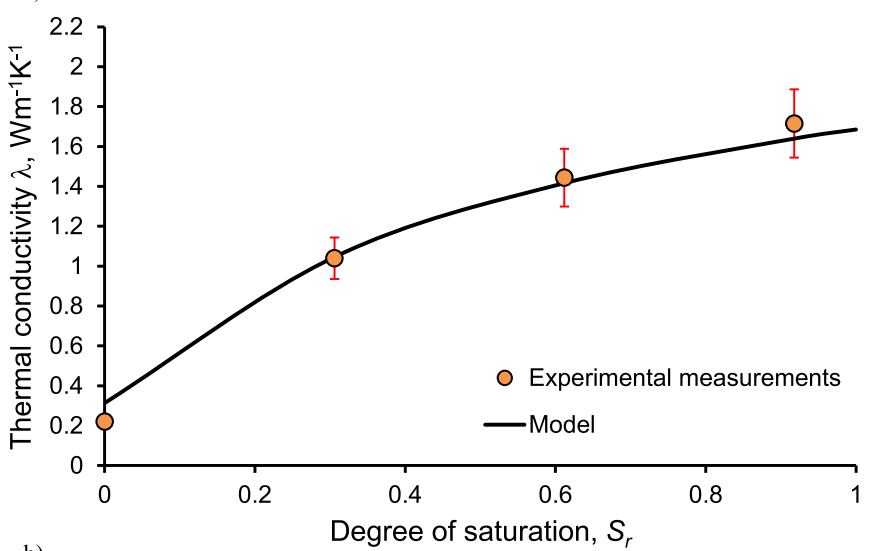

b)

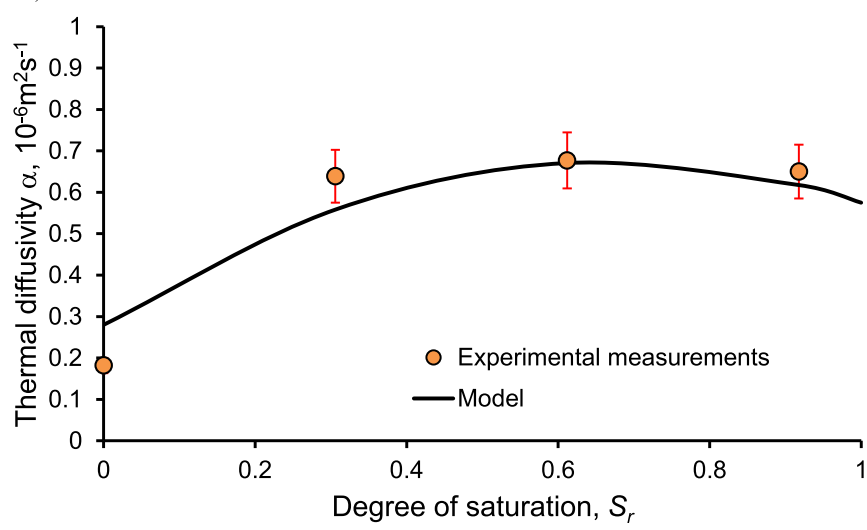

Fig. 8. Comparison of the theoretical models and the measurements of windblown sandy soil thermal properties: a) thermal conductivity $\lambda$, and b) thermal diffusivity $\alpha$, performed with KD2 Pro method.

$K_{\lambda}=\frac{\kappa \cdot \mathrm{Sr}}{1+(\kappa-1) \cdot \mathrm{Sr}}$

where $\kappa$ is a texture dependent parameter which varies linearly with sand content $[41,42]$ :

$\lambda_{\text {sat }}=e x_{\mathrm{s}}+f$

where $e$ and $f$ are constant parameters fitted with literature data [40] which are 4.4 and 0.4 , respectively.

The following equation for soil thermal diffusivity is proposed with regard to the degree of saturation by considering the saturated thermal diffusivity $\left(\alpha_{\text {sat }}\right)$ and the dry thermal diffusivity $\left(\alpha_{\text {dry }}\right)$ :

$\alpha=\left(\alpha_{\text {sat }}-\alpha_{\text {dry }}\right) *\left(\beta * \operatorname{Sr}-(1-\beta) * \mathrm{Sr}^{2}\right)+\alpha_{\text {dry }}$

where $\beta$ is a constant parameter taken equal to 4 .

Results from Abu-Hamdeh (2003) and Ochsner et al. (2001) $[29,39]$ show that there is no effect of initial dry density on the variation of thermal diffusivity. Therefore, a linear relationship is

Table 1

Sand content xs and dry density $\gamma_{\mathrm{d}}$ of each layer at profile of multilayered soil.

\begin{tabular}{llll}
\hline Soil no. & Soil type & Sand content $(\%)$ & Dry density $\left(\mathrm{kN} \mathrm{m}^{-3}\right)$ \\
\hline 1 & Vegeterian soil & 35 & 13.5 \\
2 & Soil backfill & 80 & 16 \\
3 & Wind-blown sand & 50 & 14.2 \\
\hline
\end{tabular}

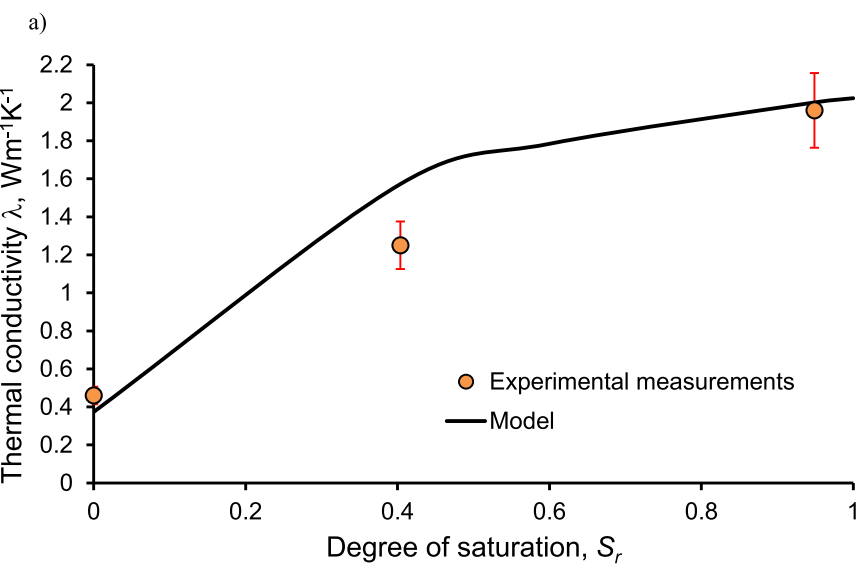

b)

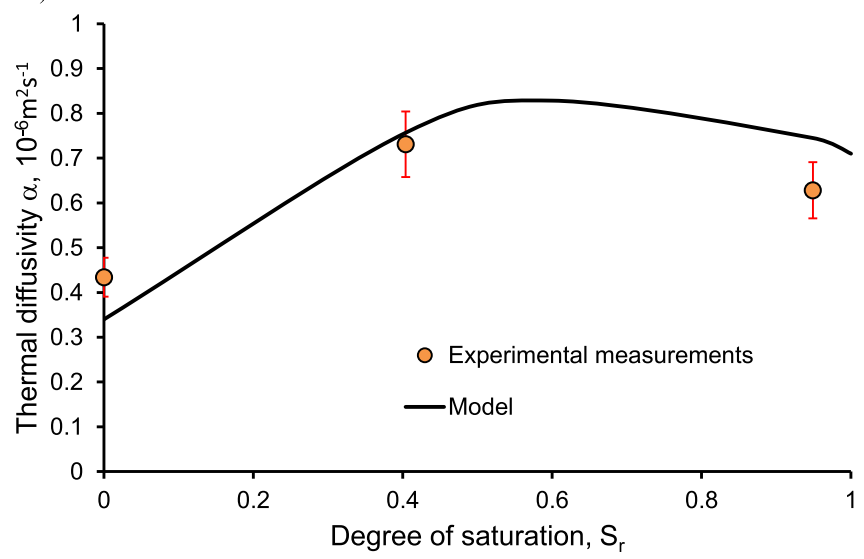

Fig. 9. Comparison of the theoretical models and the measurements of soil backfill thermal properties: a) thermal conductivity $\lambda$, and b) thermal diffusivity $\alpha$, performed with hot-plate method.

proposed for saturated and dry thermal diffusivities ( $\alpha_{\text {sat }}$ and $\alpha_{\text {dry }}$ ) with respect to sand content $x_{\mathrm{s}}$ :

$\alpha_{\text {sat }}=g x_{\mathrm{s}}+h$

$\alpha_{\mathrm{dry}}=i x_{\mathrm{s}}+j$

where $g, h, i$ and $j$ are constant parameters of values $4.5 \times 10^{-7} \mathrm{~m}^{2} \mathrm{~s}^{-1}, 3.5 \times 10^{-7} \mathrm{~m}^{2} \mathrm{~s}^{-1}, 2 \times 10^{-8} \mathrm{~m}^{2} \mathrm{~s}^{-1}$ and $1.8 \times 10^{-7} \mathrm{~m}^{2} \mathrm{~s}^{-1}$, respectively.

Applying the proposed theoretical approaches on each soil layer and using the related soil parameters in Table 1, the predicted thermal properties are compared with the laboratory measurements. Figs. 7-9 show respectively the predicted thermal properties $(\lambda$ and $\alpha$ ) of the three soil layers: vegetarian soil, wind-blown sandy soil, and soil backfill. It can be globally noted that the models agree well with the experimental measurements.

Based on Eqs. (13)-(18), $\alpha$ and $\lambda$ in each time and depth needed for the modeling of heat transfer in a multi-layered soil are then related to the space-time variations of degree of saturations $\operatorname{Sr}(z, t)$ by considering the sand content and the dry density of each layer.

\subsection{Temperature measurements in the field of multilayered soil}

As shown in Fig. 2, the monitored field is equipped with 5 temperature probes $\mathrm{TS}_{20}, \mathrm{TS}_{21}, \mathrm{TS}_{22}, \mathrm{TS}_{23}$, and $\mathrm{TH}_{50}$. Temperature probe $\mathrm{TH}_{50}$ is placed at the soil surface to measure the ambient temperature. The temperature probes $\mathrm{TS}_{20}$ and $\mathrm{TS}_{23}$ are placed at the same depth of $1.11 \mathrm{~m}$. Temperature probes $\mathrm{TS}_{21}$ and $\mathrm{TS}_{22}$ are 


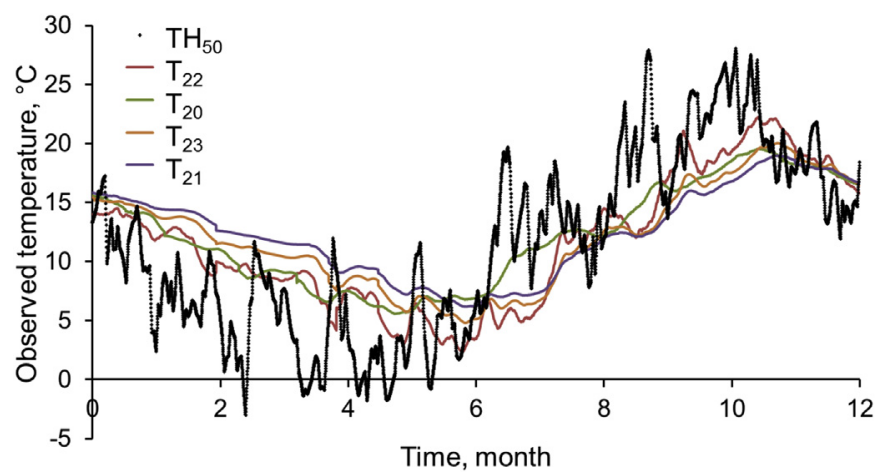

Fig. 10. Measured temperatures at the surface and different depths of soil during one year.

placed at the depths of $1.26 \mathrm{~m}$ and $0.61 \mathrm{~m}$, respectively. Fig. 10 shows the temperature variations measured by the temperature probes at the surface of soil and throughout the profile during a year.

Fig. 11 shows the temperatures measured by different probes at $t=0$ with depth $\left(T_{0}(z)\right)$. A second degree polynomial presented in Fig. 11 is used as an initial condition $T_{0}(z)$ in the following simulations.

\section{Numerical modeling}

In this section, the results of the finite difference model are presented within time for the nonhomogeneous profile, then for the homogeneous profile.

\subsection{Simulation of thermal response of multilayered soil}

Using all the input parameters of the model, i.e., water content, dry density and sand content throughout the profile, the thermal conductivity as the thermal diffusivity were determined for each layer within time. Applying initial and boundary conditions as well as continuity conditions at interface of each layer, the finite difference modeling is performed to simulate thermal response of the profile of the multilayered soil.

In order to converge the finite difference calculations (Max $\left.\left(\alpha(z, t) \mathrm{d} t / \mathrm{d} z^{2}\right)<0.5\right)$, for a $\Delta t$ equal to $90 \min (1 \mathrm{~h} 30)$ based on the experimental acquisition, the minimum $\Delta z$ should be selected higher than $0.07 \mathrm{~m}$. It was taken $0.1 \mathrm{~m}$ for the studied geometry.

Fig. 12 shows the comparison of the model with the observation by thermal probes $\mathrm{TS}_{20}, \mathrm{TS}_{21}, \mathrm{TS}_{22}$, and $\mathrm{TS}_{23}$. Generally, good agreements are obtained between the simulation results and the

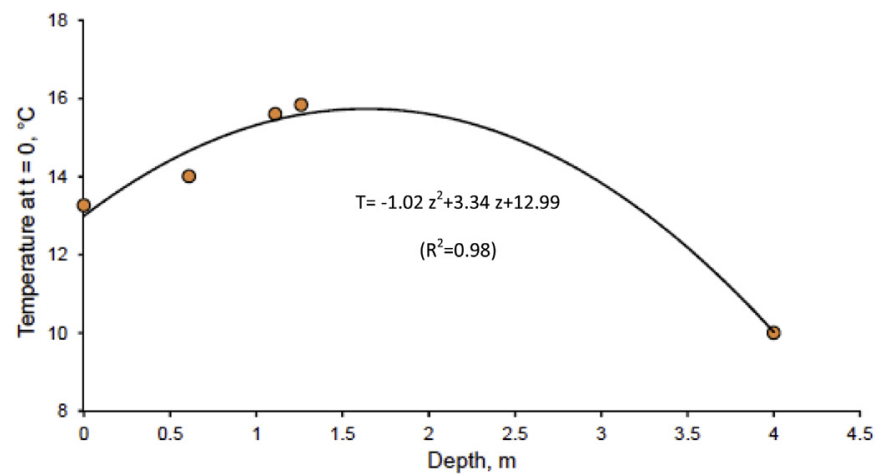

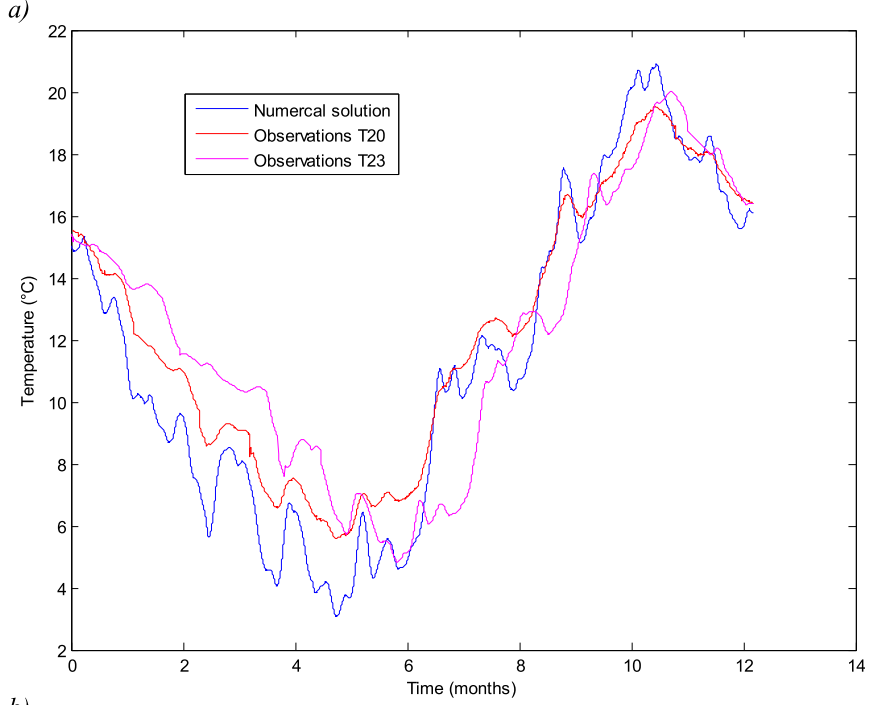

b)

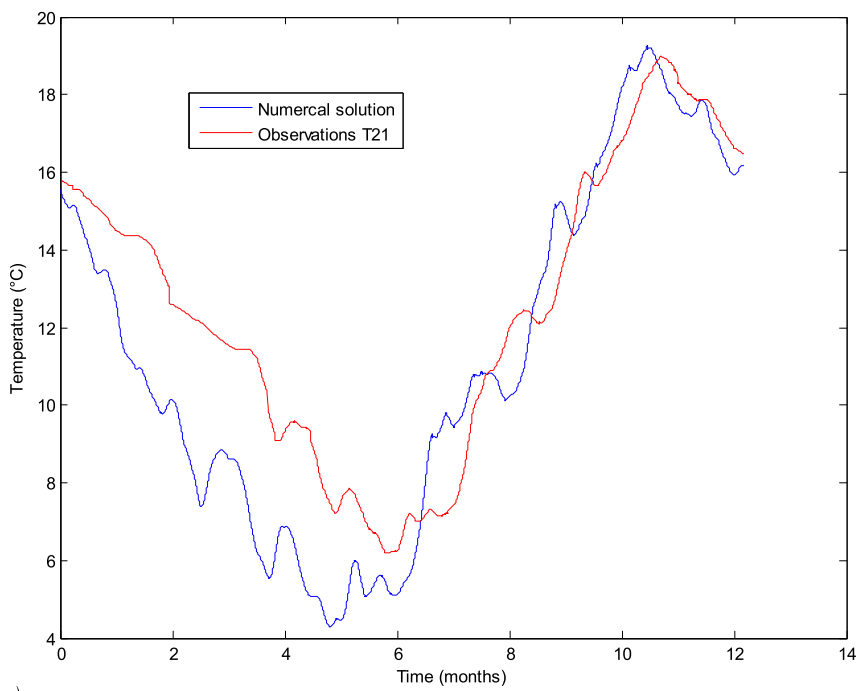

c)

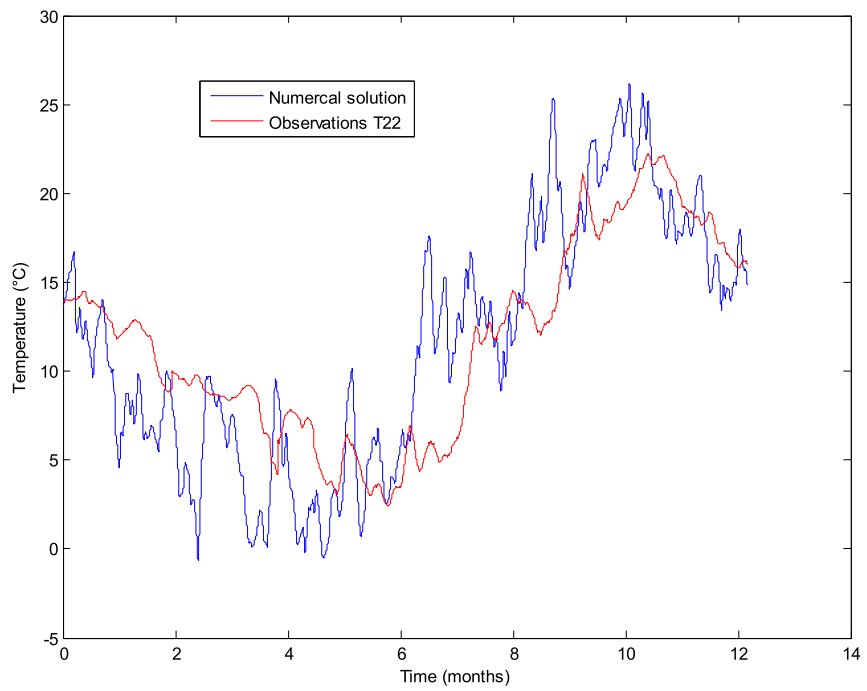

Fig. 12. Comparison of the model with the observation by thermal probes a) $\mathrm{TS}_{20}-\mathrm{TS}_{23}$, b) $\mathrm{TS}_{21}$, and c) $\mathrm{TS}_{22}$ during one year.

Fig. 11. Initial temperature variation at different depths at $t=0\left(T_{0}(z)\right)$. 


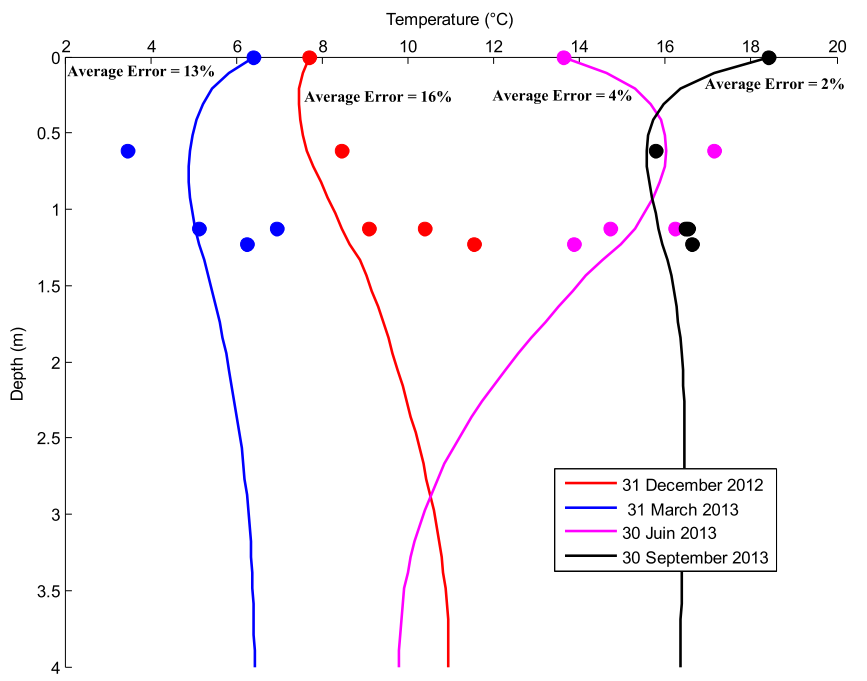

Fig. 13. Comparison of the model with the thermal probe measurements on four seasons throughout the profile.

experimental data. However, a small lag is observed between those simulation and experimental results. This is due to the continuum effects of heat transfer phenomenon by which the initial temperature of the problem is subjected to the effect of the temperature field history existed before the initial condition.

Fig. 13 shows the comparison of the model with the observations carried out on four seasons. It can be noted that the adiabatic condition (see Eq. (2)) at the depth of $4 \mathrm{~m}$ just above the ground water level is obtained. Generally, the results show that the model can estimate well thermal response of the multi-layered soil particularly for the last seasons with the average error less than $5 \%$ mainly due to the less time lagging for this period.

\subsection{Comparison between nonhomogeneous and homogeneous soil cases}

Until now, the modeling of the nonhomogeneous multilayered soil with different characteristics in each layer was studied. It is essential to compare the nonhomogeneous soil with the homogenous one to evaluate the effects of non-homogeneity on the soil thermal response.

Here, the same soil profile shown in Fig. 2 is considered as a homogeneous soil with similar thermal characteristics throughout the profile. Three cases are considered: (I) thermal diffusivity of the soil profile is taken as the maximum value of the variable thermal diffusivity in depth during the period of one year, i.e., $\alpha_{\max }=\max \left(\alpha_{p ; k}\right)$, (II) thermal diffusivity of the soil profile is taken as the minimum value of the variable thermal diffusivity in depth during the period of one year, i.e., $\alpha_{\min }=\min \left(\alpha_{p ; k}\right)$, and (III) thermal diffusivity of the soil is taken as the average value, i.e., $\alpha_{\text {average }}=\left(\sum_{p=1}^{n} \sum_{k=1}^{m} \alpha_{p, k}\right) / N$ where $N=p \times k$ is the total number of nodes $p$ and $k$.

Fig. 14a shows the distribution of degree of saturation throughout the profile of nonhomogeneous soil in its minimum value $\left(\mathrm{Sr}_{\mathrm{min}}\right)$ in 15 August 23 and maximum value in 1 June 2013 $\left(\mathrm{Sr}_{\max }\right)$ associated to the previously presented water content profile in Fig. 5 based on Eq. (11). The distribution of thermal diffusivity associated for $\mathrm{Sr}_{\min }$ and $\mathrm{Sr}_{\max }$ is shown in Fig. 14b. Thermal diffusivity of nonhomogeneous soil at $\mathrm{Sr}_{\min }$ and $\mathrm{Sr}_{\max }$ varies between the so-called values of $\alpha_{\min }$ and $\alpha_{\max }$. Thermal diffusivity of soil profile at $\mathrm{Sr}_{\max }$ is generally smaller than that of $\mathrm{Sr}_{\min }$. Such phenomenon is due to the fact that the degree of saturation of the

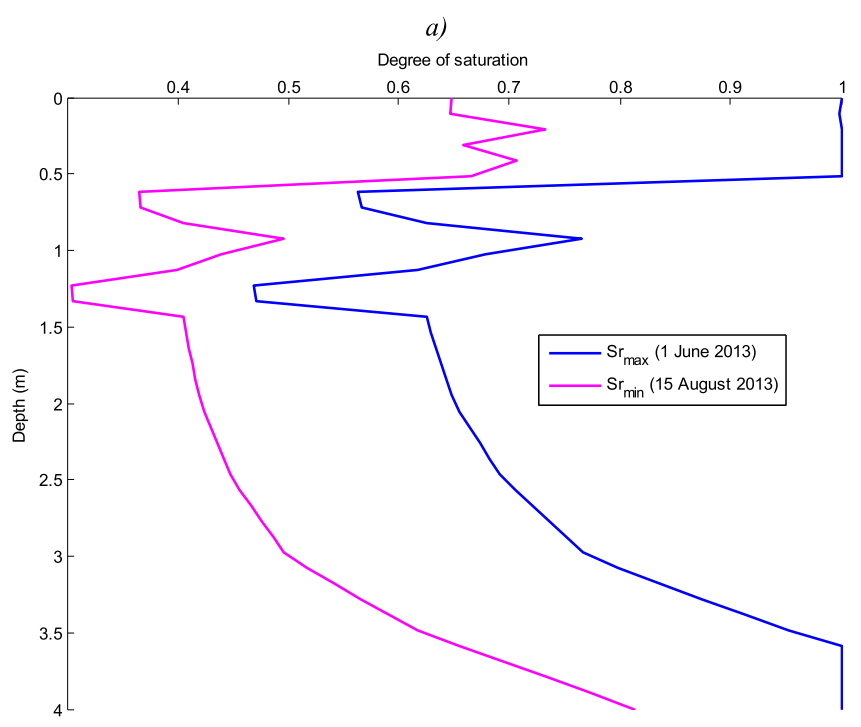

b)

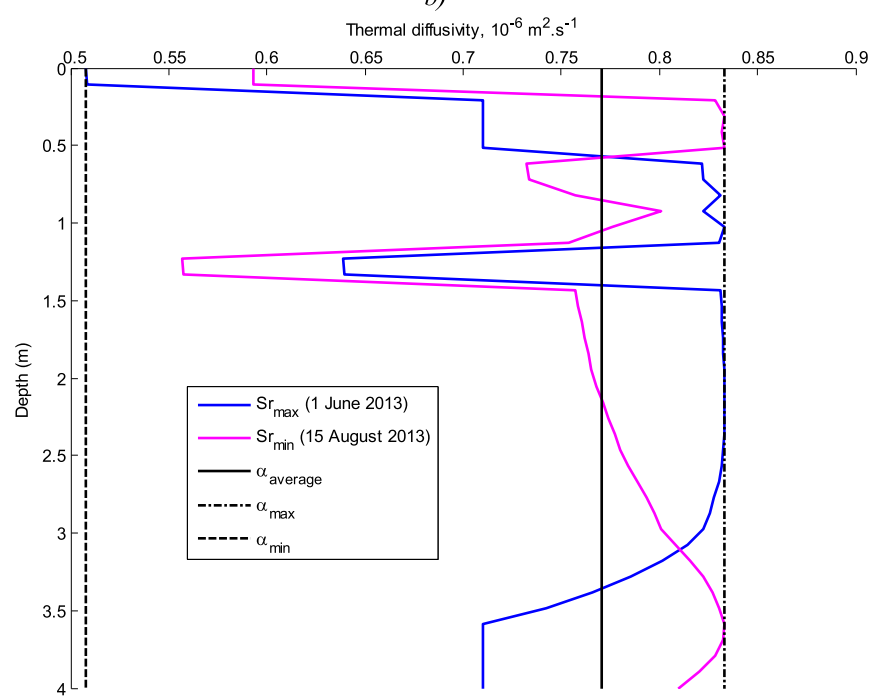

Fig. 14. a) Variation of degree of saturation at minimum and maximum values of $\mathrm{Sr}$. (b) Variation of thermal diffusivity throughout the nonhomogeneous soil profile at maximum and minimum values of $\mathrm{Sr}$.

profile varies between 0.5 and 1.0. In this range of degree of saturation, the thermal diffusivity decreases with respect to the degree of saturation (after $\mathrm{Sr}=0.5$ ) for the three soil types (see Figs. 7b, 8b and $9 \mathrm{~b}$ ). For the degree of saturation less than 0.5 , thermal diffusivity of soil increases with degree of saturation while there are small ranges of thermal diffusivity when thermal diffusivity at $\mathrm{Sr}_{\max }$ is larger than that of $\mathrm{Sr}_{\text {min }}$

Figs. 15 and 16 show temperature distribution throughout the homogeneous and nonhomogeneous soil profile on 1 December 2012 when the temperature is close to $0^{\circ}$ (temperature below zero was not considered in this study because of the complexity of heat transfer phenomena in the frozen soils) and 15 June 2013 when there is a maximum value of temperature. The experimental observations were also reported in these figures. Figs. 15a and 16a show that temperature distribution of the nonhomogeneous soil profile with variable thermal diffusivity varies between the temperature distributions of homogeneous soil at minimum and maximum values of thermal diffusivity. It shows the effect of nonhomogeneity on thermal response of soil. Figs. 15b and 16b show that the temperature distribution of the nonhomogeneous soil with 


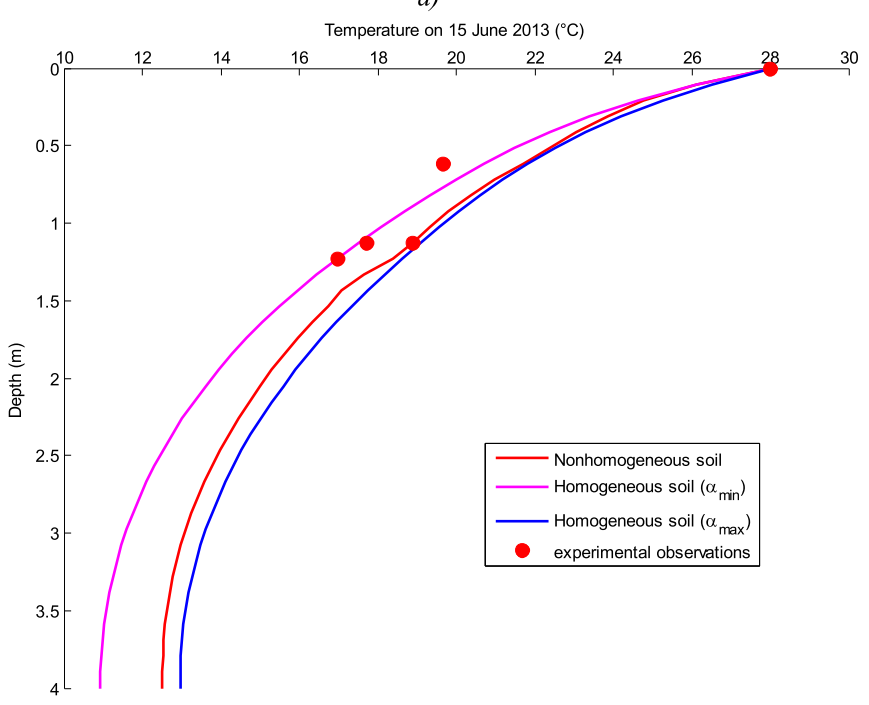

b)

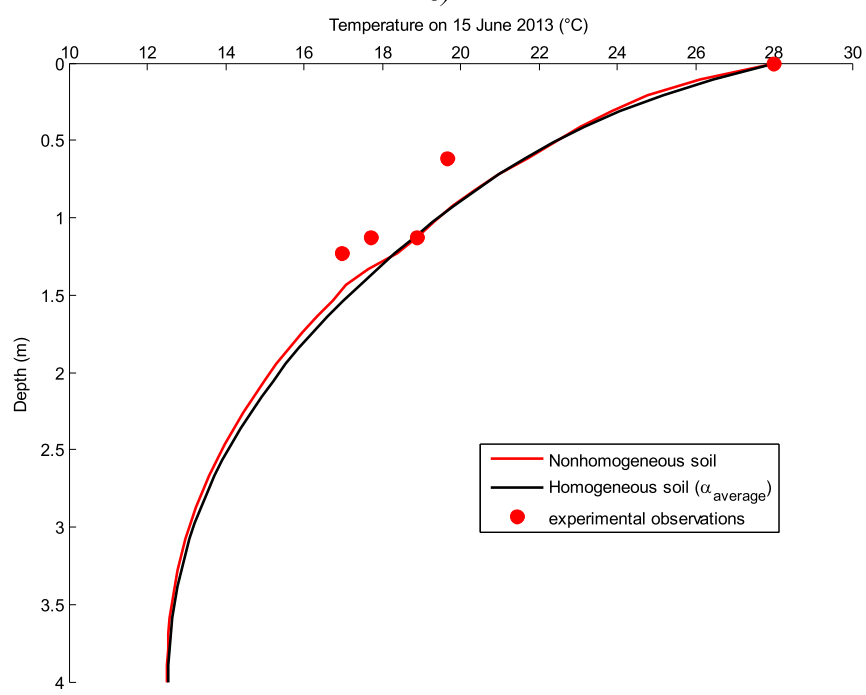

Fig. 15. Temperature distribution of nonhomogeneous soil (model and observation) compared with a) soil maximum and minimum thermal diffusivity and b) soil average thermal diffusivity, on 1 December 2012.

variable thermal diffusivity becomes almost the same value as the temperature distribution of the homogeneous soil with the average value of thermal diffusivity. But, it should be mentioned that knowing the average value of thermal diffusivity of the homogeneous soil requires thermal diffusivity values of each layer in the entire profile.

\section{Conclusion}

This study deals with a finite difference modeling of heat transfer in unsaturated multilayered soil while hydrothermal properties of soil differ in each layer.

A profile of thermal diffusivity within time is assigned to each node in finite difference formulation. The numerical model requires easily accessible input parameters such as water content, dry density, and sand content of the soil profile. It is coupled with the reliable theoretical approaches which estimate thermal properties of soil such as thermal conductivity and thermal diffusivity.

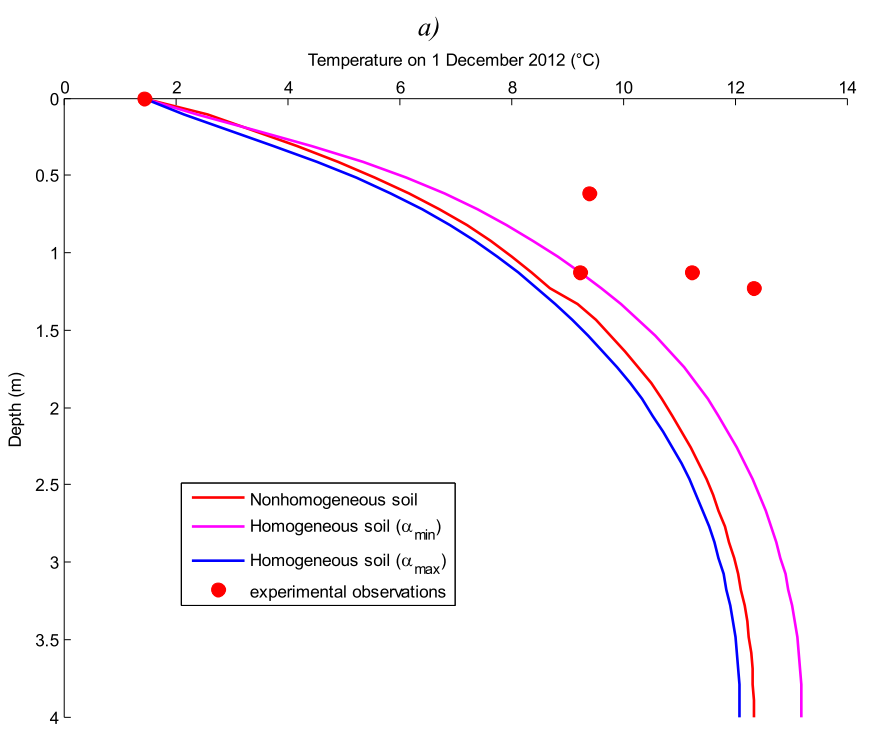

b)

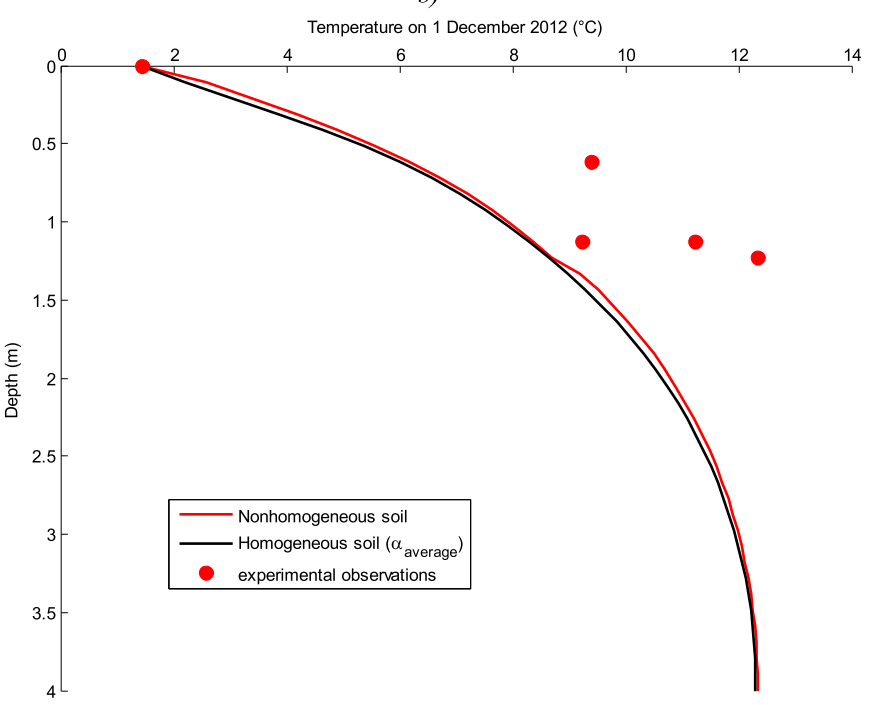

Fig. 16. Temperature distribution of nonhomogeneous soil (model and observation) compared with a) soil maximum and minimum thermal diffusivity and b) soil average thermal diffusivity, on 15 June 2013.

A comparison of the numerical results with the results of in-situ thermal probe measurements shows that the model can well estimate heat distribution within a multilayered soil.

Moreover, a study is performed on the effect of nonhomogeneity on soil thermal response. The soil with an average value of thermal diffusivity produces a thermal response close to nonhomogeneous profile. However, it is worthwhile noting that knowing the average value of thermal diffusivity requires thermal characteristics of each layer in the nonhomogeneous profile.

Such a study on the thermal response of multilayered soil can be considered on the study of the performance of geothermal borehole heat exchangers installed in soils with variable hydrothermal properties.

\section{Acknowledgments}

This work was funded by the European Commission Initiative INTERREG IV, Upper Rhine Programme (project B20, TEM3). 


\section{References}

[1] Al-Khouri R. Computational modeling of shallow geothermal systems. Multiphysics modeling, vol. 4. CRC Press; 2012.

[2] Al-Ajmi F, Loveday D, Hanby V. The cooling potential of earth-air heat exchangers for domestic buildings in desert climate. Build Environ 2006;41: 235-44.

[3] Costa V. Thermodynamic analysis of building heating or cooling using the soil as heat reservoir. Int J Heat Mass Transfer 2006;403(49):4152-60.

[4] Ghosal M, Tiwari G. Modeling and parametric studies for thermal performance of an earth to air heat exchanger integrated with a greenhouse. Energy Convers Manag 2006;47:1779-98.

[5] Hillel D. Fundamentals of soil physics. San Diego, CA: Academic Press Inc, 1980.

[6] Hillel D. Introduction to soil physics. San Diego, CA: Academic Press Inc.; 1982

[7] Marshall T, Holmes J. Soil physics. 446 New York: Cambridge University Press; 1988.

[8] Mihalakakou G, Santamouris M, Askimakopoulos D, Argiriou A. On the ground temperature below buildings. ASME - J Solar Energy Eng 1995;55: 355-62.

[9] Tsoukpoe K, Liu H, Le Pierre's N, Luo L. A review on long-term sorption solar energy storage. Renew Sustain Energy Rev 2009;13:2385-96.

[10] Zhang H, Ge X, Ye H, Jiao D. Heat conduction and heat storage characteristics of soils. Appl Therm Eng 2007;27:369-73.

[11] Choi JM, Park YJ, Kang SH. Temperature distribution and performance of ground-coupled multi-heat pump systems for a greenhouse. Renew Energy May 2014;65:49-55.

[12] You T, Wang B, Wu W, Shi W, Li X. A new solution for underground therma imbalance of ground-coupled heat pump systems in cold regions: heat compensation unit with thermosyphon. Appl Therm Eng March 2014;64(1-2):283-92.

[13] Campanella R, Mitchell J. Influence of temperature variation on soil behavior. ASCE J SMFD 1968;94:3.

[14] Farouki O. Thermal properties of soils. US: United States Corps of Engineers, Cold Regions Research and Engineering Laboratory; 1981.

[15] Leong W, Tarnawski R, Aittomaki A. Effect of soil type and moisture content on ground heat pump performance. Int J Refrigeration 1998;21.

[16] Slegel D, Davis L. Transient heat and mass transfer in soils in the vicinity of heated porous pipes. ASME - Trans J Heat Transfer 1977:486:99.

[17] Cole K, Beck J, Haji-Sheikh A, Litkouhi B. Heat conduction using Green's functions. Series in computational methods and physical processes in mechanics and thermal sciences. New York: Taylor \& Francis Group; 2010.

[18] Mihalakakou G. On estimating soil surface temperature profiles. Energy Build 2002;34:251-9.

[19] Ozgener L. Exegetic assessment of EAHEs for building heating in turkey: a greenhouse case study. Energy Policy 2010;38:5141-50.

[20] Ozgener L. A review on the experimental and analytical analysis of earth to air heat exchanger (EAHEs) systems in turkey. Renew Sustain Energy Rev 2011;15:4483-90.

[21] Ogunlela AO. Modelling soil temperature variations. J Agric Res Dev 2003: 100-9.
[22] Florides G, Kalogirou S. Annual ground temperature measurements at various depths. 8th REHVA World Congress, Clima, Lausanne, Switzerland. 2005.

[23] Kusuda T. The effect of ground cover on earth temperature. In: Proceedings of conference on alternatives in energy conservation: the use of earth-covered buildings; 1975. p. 9-12 [Forth Worth, Texas].

[24] Mihalakakou G. On the application of the energy balance equation to predict ground temperature profiles. ASME - J Solar Energy Eng 1997;60:181-90.

[25] Campbell G. Soil physics with basic: transport models for soil plant systems. New York: Elsevier Sci. Publ. Co.; 1985.

[26] De Vries D. Thermal properties of soil. In: Physics of plant environment. Amsterdam: North-Holland; 1963. p. 210-35.

[27] Johansen O. Thermal conductivity of soils. Doctoral dissertation. Trondheim: Norwegian University of Science and Technology; 1977.

[28] Kersten M. Thermal properties of soils. Engineering Experiment Station; 1949. p. 52.

[29] Ochsner TE, Horton R, Ren T. A new perspective on soil thermal properties. Soil Sci Soc Am J 2001;65:1641-7.

[30] Roxy MS, Sumithranand VB, Renuka G. Variability of soil moisture and its relationship with surface albedo and soil thermal diffusivity at Astronomical Observatory, Thiruvananthapuram, south Kerala. J Earth Syst Sci 2010;119: 507-17.

[31] Gao Z, Fan X, Bian L. An analytical solution to one-dimensional thermal conduction-convection in soil. Soil Sci 2003:168:99-107.

[32] Penrod E, Elliot J, Brown W. Soil temperature variation (1952-1956) at Lexington, Kentucky. Soil Sci 1960;90:275-83.

[33] Wang Z, Bou-Zeid E. A novel approach for the estimation of soil ground heat flux. Agric For Meteorol 2012;154:214-21.

[34] Ozgener O, Ozgener L, Tester J. A practical approach to predict soil temperature variations for geothermal (ground) heat exchangers applications. Int J Heat Mass Transf 2013:62:473-80.

[35] KD2-Pro. KD2 pro thermal properties analyzer, operator's manual. Version 10 2011. p. $1-68$.

[36] Carslaw AJ. Conduction of heat in solids. 2nd ed. London: Oxford; 1959.

[37] Kluitenberg G, Ham J, Bristow K. Error analysis of the heat pulse method for measuring soil volumetric heat capacity. Soil Sci Soc Am J 1993;57:1444-51.

[38] Goldstein RJ, Eckert ERG, Ibele WE, Patankar SV, Simon TW, Kuehn TH, et al. Literature review article. Int J Heat Mass Transfer 1998;44(2):253-366. 14 August 2001.

[39] Abu-Hamdeh NH. Thermal properties of soils as affected by density and water content. Biosyst Eng 2003;86:97-102.

[40] Lu S, Ren T, Gong Y, Horton R. An improved model for predicting soil thermal conductivity from water content at room temperature. Soil Sci Soc Am J 2007; $71: 8-14$.

[41] Nikoosokhan S, Nowamooz H, Chazallon. Seasonal heat storage in unsaturated soils with variable thermal properties. International workshop on Geomechanics and Energy, EAGE, Lausanne, Switzerland. 2013.

[42] Nikoosokhan S, Nowamooz H, Chazallon. Temperature variations in unsaturated soils with variable hydrothermal properties. Eur J Soil Sci 2014 [in press].

[43] Coté J, Konrad J-M. A generalized thermal conductivity model for soils and construction materials. Can. Geotech. J. 2005;42:443-58. 